\title{
Effect of low-intensity electromagnetic radiation on structurization properties of bacterial lipopolysaccharide
}

\author{
Grigory E. Brill, Anna V. Egorova, Irina O. Bugaeva, Sergey A. Dubovitsky *, Sergey V. Vlaskin * \\ Saratov State Medical University n.a. V. I. Razumovsky, Saratov, Russia \\ * Telemak Inc., Saratov, Russia
}

Accepted 25 August 2014

Original Text @ Brill GE, Egorova AV, Bugaeva IO, Dubovitsky SA, Vlaskin SV, 2013, published in Saratov Journal of Medical Scientific Research 2013; 9(4): 637-640.

\begin{abstract}
Purpose - to investigate the effects of low-intensity electromagnetic radiation on the process of dehydration selforganization of bacterial lipopolysaccharide (LPS). Material and Methods - The method of wedge dehydration has been used to study the structure formation of bacterial LPS. Image-phases analysis included their qualitative characteristics, as well as the calculation of quantitative indicators, followed by statistical analysis. Results - Low-intensity ultra high frequency (UHF) radiation (1 GHz, $0.1 \mu \mathrm{W} / \mathrm{cm} 2,10 \mathrm{~min}) \mathrm{has}$ led to the changes in the suspension system of the LPS-saline reflected in the kinetics of structure formation. Conclusion $-1 \mathrm{GHz}$ corresponds to the natural frequency of oscillation of water clusters and, presumably, the effect of UHF on structure of LPS mediates through the changes in water-salt environment. Under these conditions, properties of water molecules of hydration and possibly the properties of hydrophobic and hydrophilic regions in the molecule of LPS, which can affect the ability of toxin molecules to form aggregates change. Therefore the LPS structure modification may result in the change of its toxic properties.
\end{abstract}

Keywords: bacterial lipopolysaccharide, self-organization, low-intensity electromagnetic radiation

Cite as Brill GE, Egorova AV, Bugaeva 1O, Dubovitsky SA, Vlaskin SV. Effect of low-intensity electromagnetic radiation on structurization properties of bacterial lipopolysaccharide. Russian Open Medical Journal 2014; 3: 0303.

Correspondence to Anna V. Egorova. Phone: +79172106980. E-mail: AV_Egorova @bk.ru

\section{Introduction}

Bacterial lipopolysaccharide (LPS) is an amphiphilic biopolymer which contains hydrophilic (O-specific chains, core oligosaccharide) and hydrophobic (A lipid) fragments. It influences the macroorganism by stimulating leucocytes, thrombocytes and endothelial cells, increasing of interleukine producing, tumour necrosis factor $\alpha$, and number of other mediators. LPS also makes it evident in activation of a complement system and clotting factor, which may cause disseminated intravascular coagulopathy, endotoxic shock and acute multiple organ failure [1, 2].

Pathogenic features of LPS depend not only on its chemical structure, they are significantly determined by a 3D-organization of supramolecular complexes produced by an LPS molecule with various components of biofluids [3].

An actual aim is to find a possibility to reduce pathogenic effects of bacterial LPS. In order to reduce a LPS toxicity and pathogenic effect different chemical substances are used (cation amphiphilic molecules, synthetic peptides, polyamines, non-toxic polysaccharide chitosan), which causes producing macromolecular complexes [4-6]. Today it is proved a modifying effect of a lowintensity radiation of red and violet spectrum areas on a process of a bacterial LPS structuring in water suspension and normal saline [7]. However, changing of LPS self-organization capability by producing of macromolecular complexes under electromagnetic radiation of ultra-wave part of the spectrum, has not studied yet.
Aim: to study a modifying effect of a low-intensity radiation of $1 \mathrm{GHz}$ frequency on a structuring capability of bacterial LPS.

\section{Material and methods}

LPS E.coli 055: B5 (Sigma, USA) was used in the study. LPS was cut ex tempore with a $0.9 \%$ normal saline $(20 \mathrm{mg} / \mathrm{ml})$. The suspension $(2 \mathrm{ml})$ was divided into 2 probes: one of them exposed by a 10 -minute electromagnetic radiation $(1 \mathrm{GHz}$, power density $0.1 \mu \mathrm{W} / \mathrm{cm}^{2}$ ) and a control one. Radiation was performed by «Akvaton-2» apparatus (Telemak Inc., Saratov, Russia). The irradiator horn was placed $10 \mathrm{~cm}$ from the object.

To study the process of spontaneous LPS structuring there was used method of cone dehydratation [8] based on studuing of a structural facies formed after a drop of preparation drying in standard conditions. $1 \mu \mathrm{l}$ of a studied suspension (control probe) was placed on a dry, clean and defatted object-plate. For a comparative analysis 6-8 drops have been usually placed. Next the object-plate with the preparation was put into an incubator in a dead-level position and dried at $37^{\circ} \mathrm{C}$ during 30 minutes. Experimental preparations had been prepared analogically with the control probes.

After drying, preparations came under a microscopic study. Light microscopy with a photorecording of a structural facies and saving information in the computer (Zeiss, Germany). Image-analysis of facies included qualitative characteristics and calculation of quantitative indices followed by a statistical processing. 

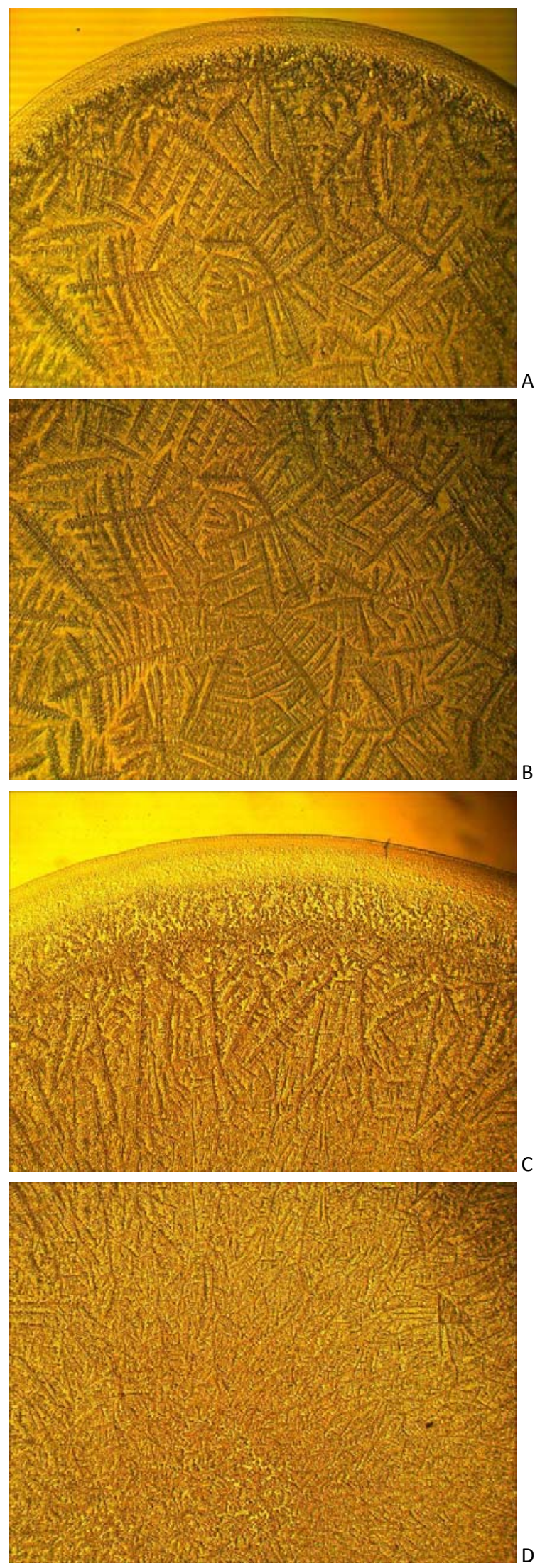

Figure 1. Influence of UHF-radiation on a structuring of bacterial LPS in a normal saline: A - control, peripheral and para-rim areas; B - control, central area; C - UHF-radiation, peripheral and para-rim areas; D - UHFradiation, central area.

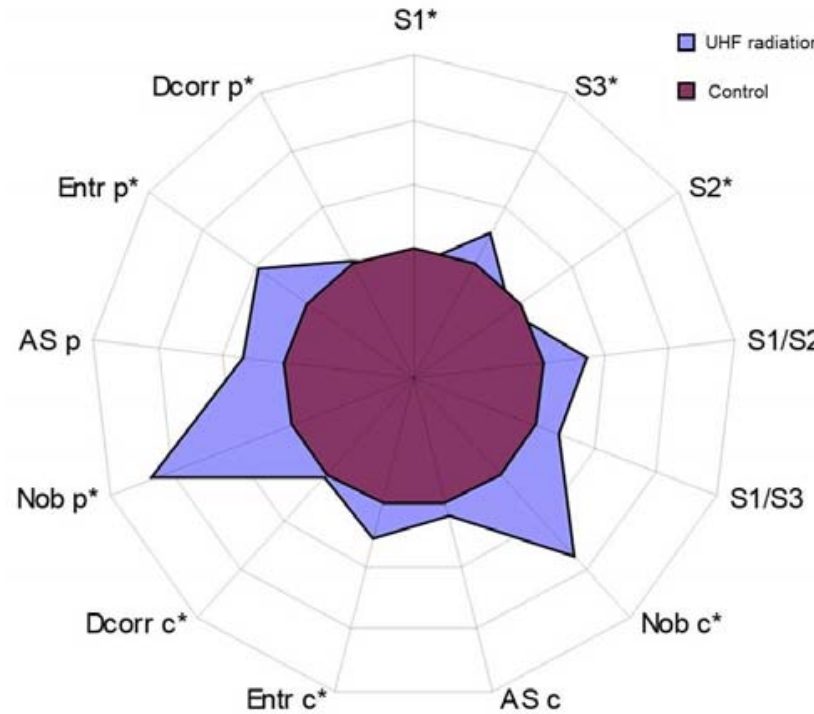

Figure 2. Changes of quantitative parameters of facies of bacterial LPS after UHF-radiation; control $-100 \%$.

In facies processing a special computer program was used, and the following parameters had been calculated: $S_{1}$ - peripheral rim area normalized to the total facies area: $S_{2}$ - intermediate zone area normalized to the total facies area; $S_{3}$ - central zone area normalized to the total facies area; $S_{1} / S_{2}$ - decentration of an intermediate zone relative to facies rim center; $S_{2} / S_{3}-$ decentration of a central zone relative to facies rim center. In the central and intermediate facies zones had been calculated: $\mathrm{N}-\mathrm{a}$ number of combs in a typical facies fragment; Average size (AS) an average size of combs in a typical facies fragment; Entr. irregularity of facies surface in a typical fragment; D corr. correlation dimension of a typical fragment.

Quantitative parameters had been statistically processed with arithmetical mean (M) calculation and its error $(\mathrm{m})$ using statistical software package Prizm-4. Statistical significance of averages had been calculated by Student's t-test. The difference was significant at $p<0.05$.

\section{Results}

Pattern of facies, getting after dehydration of a non-irradiated LPS suspension in normal saline, distinguished by a variety of structural elements. Here three zones had been directly visualized: elevated rim around facies (peripheral zone), para-rim (or intermediate zone) and central areas (Figure 1).

The rim had a slight structuring, and only in some of its areas there were small lumpy formations. The para-rim zone took a small part of a facies area and was characterized by a presence of small line dendritic and ferny elements (Figure 1A). In the central zone large treeng elements had been revealed, contained linear frame axis with 90 branches (Figure 1B).

The low-intensity electromagnetic radiation of the LPS suspension caused a significant modification of a structuring process. A typical change in a facies picture was noticed: space allocation density in the para-rim zone had increased, their structural finess reduced (Figure 1C). The linear dendritic elements in the central zone had been significantly reduced in size, so, this facies area was almost homogeneous (Figure 1D). In close 
proximity to the para-rim zone there had been radial elements with a wavy axial directional line and its short branch lines on various angles (Figure $1 \mathrm{C}$ ).

The results of the quantitative processing of facies after cone dehydratation of LPS suspension in the control probe and after the ultra high frequency (UHF) radiation are presented in the Figure 2.

As we an see from the picture, a low-intensity radiation of $1 \mathrm{GHz}$ frequency caused changes in reference dimensions of facies areas: peripheral and para-rim zones were reduced $(p<0.01$ and $p<0.001$ respectively), while the central area size had increased by $20 \%(p<0.01)$. After the UHF-radiation the number of comb objects in the central and para-rim facies areas had increased about by 2 times $(p<0.05)$. However their average size did not suffer evident changes. The Entr. parameter, characterized structural inhomogeneity of the central facies zone $(p<0.05)$, had increased by 1.2 times on this background, and the Entr. parameter of the para-rim area ahd increased by $32 \%(p<0.02)$. Structuredness (correlation dimensionality) of the both analysed zones had statistically changed $(p<0.02)$.

\section{Discussion}

The results of the given experiments show that the lowintensity radiation of $1 \mathrm{GHz}$ frequency and the $0.1 \mu \mathrm{W} / \mathrm{cm}^{2}$ power density, going on for $10 \mathrm{~min}$, causes changes in "LPS - normal saline" system. These changes impact on a structuring kinetics. The $1 \mathrm{GHz}$ frequency coincides to a natural frequency of a water cluster variation [9], and, probably, the UHF-radiation effect on a LPS structuring is mediated by the change of a salt-water media. In these conditions hydration properties of water molecules change, and, probably, properties of hydrophobic and hydrophilic areas in the LPS molecule, which may impact on the property of toxin molecule to produce aggregates. Whereas, modification of a lipopolysaccharide structure may cause change of its toxic properties. The proving is the recent study in which there had been displayed that irradiation of the bacterial LPS by the lowintensity laser red emission had modified spontaneous process of structuring in vitro, and also reduced pathogenic LPS effects in vivo, decreasing activity of thrombocytes, leucocytes and endothelial cells. The irradiation reduces also evidence of microcirculatory defects developing after endotoxin ingressing into the systemic circulation [10].

\section{Conclusion}

The fact of a possible reducing of pathogenic effects of bacterial endotoxin exposed by physical impacts, perhaps, shows changes in architectonics of a toxic molecule, the changes reflect on the LPS capability to produce supermolecular complexes determining its ability to interact with biosubstrate.

Conflict of interests: none declared.

\section{References}

1. Tabolin VA, Yakovlev MYu, II'ina AYa, Likhoded VG, Lazareva SI. Pathogenetic mechanisms and kinetic aspects of thermostable endotoxin effect on gut organisms. Rus Med Zhurn 2003; 11: 126-129. Russian

2. Dauphinee SM, Karsan A. Lipopolysaccharide signaling in endothelial cells. Lab Invest 2006; 86(1): 9-22. (doi: 10.1038/labinvest.3700366) (PMID: 16357866)
3. Brandenburg K, Wiese A. Endotoxins: relationships between structure, function, and activity. Curr Top Med Chem 2004; 4: 1127-1146. (PMID: 15279605) (doi: 10.2174/1568026043388213)

4. Davydova VN, Yermak IM, Gorbach VI, Krasikova IN, Solov'eva TF. Interaction of bacterial endotoxins with chitosan. Effect of endotoxin structure, chitosan molecular mass, and ionic strength of the solution on the formation of the complex. Biochemistry (Moscow) 2000; 65(9): 1082-1090. (PMID: 11042502)

5. Ermak IM, Davydova VN, Gorbach VI, Berdyshev EL, Kuznetsova TA, Ivanushko IA, et al. Modification of biological activity of lipopolysaccharide in the complex with chitosan. Bull Exp Biol Med 2004; 137: 379-381. (doi: 10.1023/B:BEBM.0000035136.61014.c2) (PMID: 15452608)

6. Yermak IM, Davydova VN. Interaction of bacterial lipopolysaccharides with host soluble proteins and polycations. Biochemistry (Moscow) Supplement Series A: Membrane and Cell Biology 2008; 2(4): 279-295. (doi: 10.1134/S1990747808040016)

7. Brill GE, Agadzhanova KV, Pravdin AB, Postnov DJe. Effect of laser radiation with various types of polarization on structural properties of bacterial lipopolysaccharide. Fotobiologija i Fotomedicina 2011; 8(2): 77-81. Russian

8. Shabalin VN, Shatokhina SN. Morphology of biological fluids of a human. Moscow, Russia: Khrizostom, 2001; 303 p. Russian

9. Sunkari VG, Aranovitch B, Portwood N, Nikoshkov A. Effect of lowintensity electromagnetic field on fibroblast migration and proliferation. Electromagn Biol Med 2011; 30(2): 80-85. (doi: 10.3109/15368378.2011.566774) (PMID: 21591892)

10. Brill GE, Agadzhanova KV, Gasparyan LV, Makela AM. Laser irradiation of bacterial lipopolysaccharide modifi es its effect on microcirculation. Laser Medicine 2009; 13(4): 46-49. Russian

\section{Authors:}

Grigory E. Brill - MD, D.Sc., Professor, Department of Pathological Physiology, Saratov State Medical University n.a. V. I. Razumovsky, Saratov, Russia;

Anna V. Egorova - MD, PhD, Assistant Professor, Department of Histology, Saratov State Medical University n.a. V. I. Razumovsky, Saratov, Russia;

Irina O. Bugaeva - MD, D.Sc., Professor, Head of Department of Histology, Saratov State Medical University n.a. V. I. Razumovsky, Saratov, Russia; Sergey A. Dubovitsky - General Manager, Telemak Inc, Saratov, Russia; Sergey V. Vlaskin - PhD, Technical Manager, Telemak Inc, Saratov, Russia. 